\title{
Projecting future climate change effects on the extreme hydrological drought events in the Weihe River basin, China
}

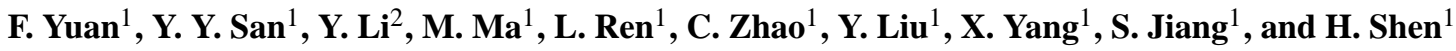 \\ ${ }^{1}$ State Key Laboratory of Hydrology-Water Resources and Hydraulic Engineering, College of Hydrology and \\ Water Resources, Hohai University, 1 Xikang Road, Nanjing, China \\ ${ }^{2}$ Patent Examination Cooperation Center of The Patent Office, SIPO, Henan, Zhengzhou China
}

Correspondence to: F. Yuan (fyuan@hhu.edu.cn)

Received: 15 April 2015 - Accepted: 15 April 2015 - Published: 11 June 2015

\begin{abstract}
In this study, a framework to project the potential future climate change impacts on extreme hydrological drought events in the Weihe River basin in North China is presented. This framework includes a largescale hydrological model driven by climate outputs from a regional climate model for historical streamflow simulations and future streamflow projections, and models for univariate drought assessment and copula-based bivariate drought analysis. It is projected by the univariate drought analysis that future climate change would lead to increased frequencies of extreme hydrological drought events with higher severity. The bivariate drought assessment using copula shows that future droughts in the same return periods as historical droughts would be potentially longer and more severe, in terms of drought duration and severity. This trend would deteriorate the hydrological drought situation in the Weihe River basin. In addition, the uncertainties associated with climate models, hydrological models, and univariate and bivariate drought analysis should be quantified in the future research to improve the reliability of this study.
\end{abstract}

\section{Introduction}

Currently droughts are the most severe disasters leading to the greatest economic losses in China. Climate change in the past few decades has altered drought frequency and characteristics such as duration and severity in many regions of China. Even in humid Southern China where droughts used to be less frequent, several long-duration, severe and expansive drought events occurred in the 2000s and 2010s, causing serious water shortage problems. Therefore it is very necessary to project the possible climate change impacts on future drought occurrence so as to provide effective guidelines for climate change adaptions. This study presents a framework to project future climate change impacts on extreme hydrological droughts in the Weihe River basin in China. As streamflow is an important index to characterize hydrological droughts, a large-scale hydrological model was driven by climate outputs from a region climate model for historical streamflow simulations and future streamflow projec- tions, and the simulated streamflow was used for univariate and copula-based bivariate drought analysis.

\section{Study area}

The Weihe River is one of major tributaries of the Yellow River in North China, with drainage area of $1.348 \times 10^{5} \mathrm{~km}^{2}$ (Fig. 1). The basin is dominated by continental monsoon climate and characterized as semi-arid region. The mean temperature ranges between 9.3 and $14.4^{\circ} \mathrm{C}$. The mean annual precipitation is $580.7 \mathrm{~mm}$. Precipitation mainly occurs from July to October, which accounts for $60 \%$ of annual precipitation. The Weihe River basin is prone to droughts. Agriculture losses due to drought disasters contribute to over $50 \%$ of the total losses. Recent climate change has deteriorated the water shortage in the basin and resulted in more severe drought events, which emphasizes the necessity to study the possible climate change impacts on regional drought events. 


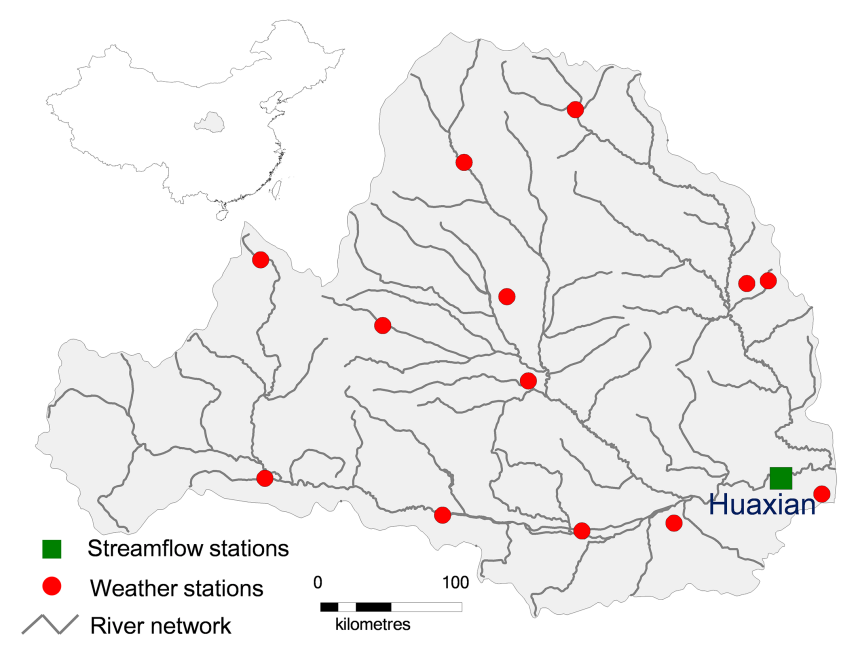

Figure 1. Meteorological and streamflow stations in the Weihe river basin.

\section{Data and methodology}

\subsection{Data}

Historical meteorological data of thirteen weather stations in the basin (Fig. 1) were obtained, which include daily records of maximum and minimum air temperature and precipitation in the years 1961-1990. Observed daily streamflow data at the Huaxian hydrologic station (controlled area: $106498 \mathrm{~km}^{2}$, Fig. 1) in the years 1961-1990 were collected. Climate data from the Providing Regional Climates for Impacts Studies (PRECIS) regional climate model (RCM) (Metoffice, 2002) climate data were adopted, which are composed of the simulated daily maximum and minimum air temperature and precipitation in the baseline years of 19611990 and in the years of 2011-2040 under A1B scenario of the Intergovernmental Panel on Climate Change (IPCC) Special Report on Emission Scenarios (SRES) at a 50-km spatial resolution. The whole basin was divided into 213 grid cells at a $0.25^{\circ}$ resoluation. Linear interpolation was performed to transform the weather station data and PRECIS-simulated forcing data to a $0.25^{\circ}$ resolution. The delta-change method was used, which employs the observed climatic dataset as the baseline climatology and superimposes the mean monthly anomalies between the PRECIS-simulated baseline and future climate on the observed historical meteorology to represent future climate data set.

\subsection{The VIC model}

The Variable Infiltration Capacity (VIC) model (Liang et al., 1994) is a physicallly-based hydrological model. It simulates radiative fluxes, turbulent fluxes of momentum, sensible heat, unsaturated liquid water transport, saturated gravitational drainage, local surface runoff, bottom drainage evapotranspiration, freezing and thawing of soil ice at each land grid cell.
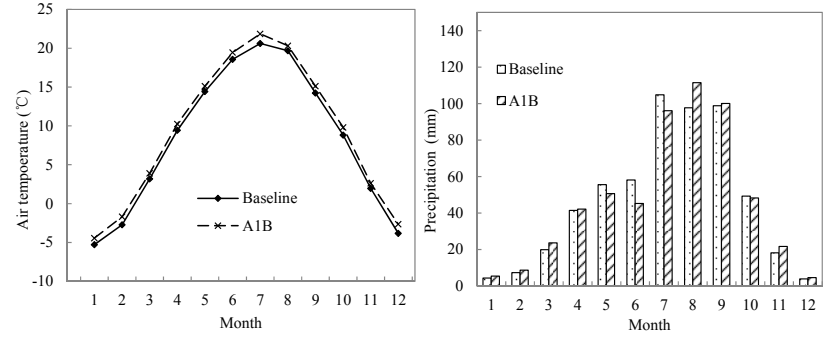

Figure 2. Basin-averaged mean monthly air temperature (left) and precipitation (right) under the baseline and A1B scenarios.

Table 1. Performance of historical streamflow simulations at the Huaxian station.

\begin{tabular}{lrrr}
\hline Periods & \multicolumn{2}{c}{ Nash-Sutcliffe coefficient } & Bias (\%) \\
\cline { 2 - 3 } & $\begin{array}{r}\text { Daily } \\
\text { simulation }\end{array}$ & $\begin{array}{r}\text { Monthly } \\
\text { simulation }\end{array}$ & \\
\hline Calibration (1961-1980) & 0.714 & 0.822 & 7.3 \\
Validation (1981-1990) & 0.725 & 0.764 & 4.6 \\
\hline
\end{tabular}

Additionally, a conceptual streamflow routing model is included to route the computed runoff depth at each grid cell to the watershed outlets by the linear reservoir method and the Muskingum routing algorithm. In this study, the gridded baseline and future climate data sets were used to drive the VIC model for daily streamflow simulations at the Huaxian station. Subsequently, the monthly simulated streamflow time series accumulated from the daily time series were employed to assess hydrological drought properties using univariate and bivariate drought distributions.

\subsection{Univariate drought distribution}

The VIC-simulated monthly streamflow time series were used to identify the hydrological drought events under the baseline (1961-1990) and A1B (2011-2040) scenarios by the theory of runs. A hydrological drought event was identified during the period when the simulated monthly streamflow is below a truncation streamflow. Following Shiau et al. (2007), the truncation streamflow in this study was defined to be the monthly medians of streamflow for the Huaxian station from 1961 to 1990 . Two drought properties, namely drought duration and severity, were identified for each event. Drought duration is the time period when streamflow is below the truncation level, and drought severity is the cumulative deviation below the truncation streamflow during the drought duration. For the analysis using univariate drought distributions, the exponential and Weibull distributions were respectively used to fit the drought duration and severity for both time periods. Accordingly, the univariate probabilities and return periods for drought duration and severity were derived for the baseline and A1B scenarios. 


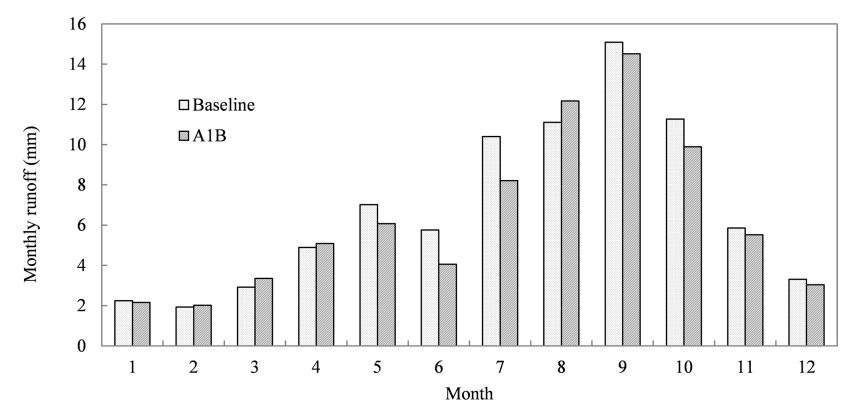

Figure 3. Basin-averaged mean monthly runoff depth under the baseline and A1B scenarios.
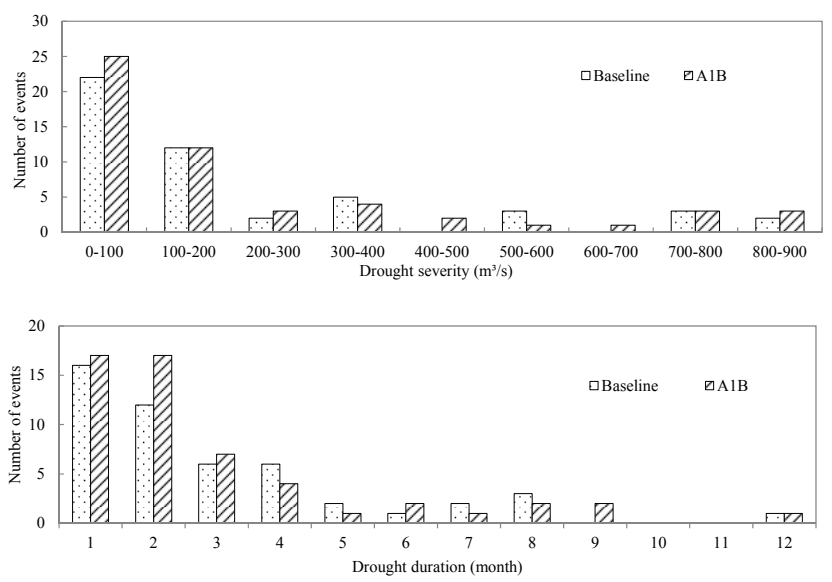

Figure 4. Statistics of number of hydrological drought events at various levels of drought severity (top) and duration (bottom).

\subsection{Bivariate drought distribution}

Copulas are functions that link univariate distribution functions to form multivariate functions (Sklar, 1959). Given the univariate drought distributions of drought duration and severity $\left(F_{\mathrm{D}}(\mathrm{d})\right.$ and $\left.F_{\mathrm{S}}(\mathrm{s})\right)$, the joint distribution for drought duration and drought severity was established using the Clayton copula (Shiau et al., 2007):

$F_{\mathrm{D}, \mathrm{S}}(\mathrm{d}, \mathrm{s})=\left(F_{\mathrm{D}}(d)^{-\theta}+F_{\mathrm{S}}(s)^{-\theta}-1\right)^{1-\frac{1}{\theta}}, \theta \geq 0$

where $F_{\mathrm{D}}(\mathrm{d})$ and $F_{\mathrm{S}}(\mathrm{s})$ are the marginal distributions for drought duration and severity, respectively; $F_{\mathrm{D}, \mathrm{S}}(\mathrm{d}, \mathrm{s})$ is the joint probability for drought duration and severity; $\theta$ is the Clayton copula parameter representing the degree of association between $F_{\mathrm{D}}(\mathrm{d})$ and $F_{\mathrm{S}}(\mathrm{s})$. With the joint distribution probability for drought duration and severity, two bivariate return periods were calculated and defined as $T_{\mathrm{DS}}^{\mathrm{AND}}$ and $T_{\mathrm{DS}}^{\mathrm{OR}} \cdot T_{\mathrm{DS}}^{\mathrm{AND}}$ represents the return period when both drought duration and severity exceed their specific values:

$T_{\mathrm{DS}}^{\mathrm{AND}}=\frac{E(L)}{P(D \geq \mathrm{d}, S \geq \mathrm{s})}=\frac{E(L)}{1-F_{\mathrm{D}}(\mathrm{d})-F_{\mathrm{S}}(\mathrm{s})+F_{\mathrm{DS}}(\mathrm{d}, \mathrm{s})}$

where $E(L)$ is the mean interarrival time of droughts, and $T_{\mathrm{DS}}^{\mathrm{OR}}$ denotes the return period when drought duration is
Table 2. Drought characteristics for different univariate return periods.

\begin{tabular}{lrrrr}
\hline $\begin{array}{l}\text { Return } \\
\text { periods }\end{array}$ & \multicolumn{2}{c}{$\begin{array}{c}\text { Drought } \\
\text { severity }\left(\mathrm{m}^{3} \mathrm{~s}^{-1}\right)\end{array}$} & \multicolumn{2}{c}{ Drought } \\
& duration (month) \\
\cline { 2 - 5 } & Baseline & A1B & Baseline & A1B \\
\hline 50 years & 913 & 986 & 11.9 & 11.9 \\
20 years & 682 & 725 & 9.0 & 9.0 \\
10 years & 512 & 536 & 6.8 & 6.8 \\
5 years & 347 & 356 & 4.6 & 4.5 \\
\hline
\end{tabular}

Table 3. RMSE of fitting four copula functions to joint distribution for severity and duration.

\begin{tabular}{lrrrr}
\hline \multirow{2}{*}{ Scenarios } & \multicolumn{4}{c}{ RMSE } \\
\cline { 2 - 5 } & $\begin{array}{c}\text { Gumbel- } \\
\text { Hougarrd }\end{array}$ & $\begin{array}{r}\text { Clayton } \\
\text { (Cook-Johnson) }\end{array}$ & Frank & $\begin{array}{r}\text { Ali- } \\
\text { Mikhail-Haq }\end{array}$ \\
\hline Baseline & 0.2071 & $\mathbf{0 . 0 3 6 3}$ & 0.1454 & 0.3007 \\
A1B & 0.2048 & $\mathbf{0 . 0 5 7 9}$ & 0.1421 & 0.3887 \\
\hline Note: the bold numbers indicate that the Clayton (Cook-Johnson) copula has the lowest
\end{tabular}
RMSE among all the four copulas.

longer than a specific value or drought severity exceeds another specific value:

$T_{\mathrm{DS}}^{\mathrm{OR}}=\frac{E(L)}{P(D \geq \mathrm{d} \text { or } S \geq \mathrm{s})}=\frac{E(L)}{1-F_{\mathrm{DS}}(\mathrm{d}, \mathrm{s})}$

\section{Results}

\subsection{Projected changes in air temperature and precipitation}

The baseline mean monthly air temperature and precipitation were compared with the projected A1B values (Fig. 2). It illustrates that a considerable increase in air temperature under A1B is projected throughout the whole year, with an averaged rise of $1.01,0.74,0.93$ and $0.85^{\circ} \mathrm{C}$ in spring, summer, autumn and winter seasons. No distinct changes in mean annual precipitation was found under both scenarios, with $558.7 \mathrm{~mm}$ for baseline and $557.3 \mathrm{~mm}$ for A1B. However, some changes in mean monthly precipitation were projected, with a slight rise in August-September and November-April, and a considerable drop in May-July.

\subsection{Projected changes in streamflow}

Historical daily streamflows at the Huaxian station (Fig. 1) were simulated using the VIC model fed with the observed precipitation and air temperature data. Table 1 shows that the VIC model can provide reasonable streamflow simulations in calibration and validation periods in terms of NashSutcliffe model efficiency coefficient and the relative error 


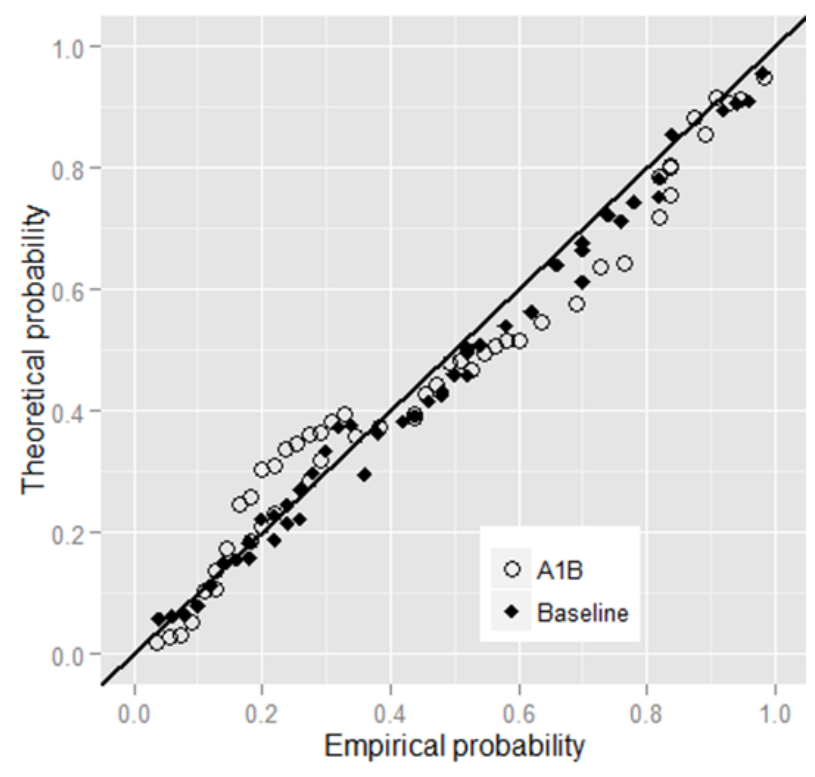

Figure 5. Empirical joint probability compared with Clayton-based theoretical probability under baseline and A1B scenarios.

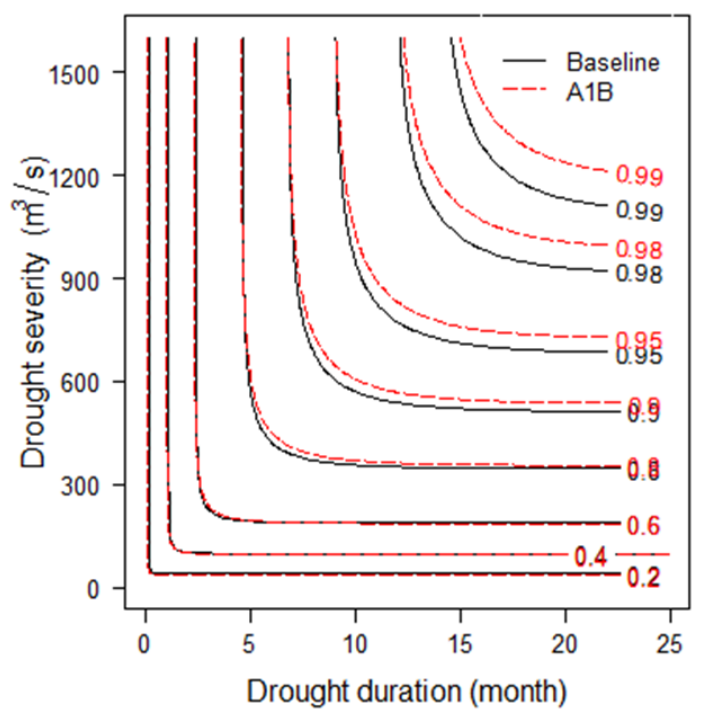

Figure 6. Contours of joint probability for drought duration and severity for baseline and A1B drought events.

between the simulated and the observed total runoff (Bias). The VIC model was used to simulate daily streamflow processes under baseline and A1B scenarios. Figure 3 indicates that basin-averaged mean monthly runoff is likely to drop in most months (May-July and September-January), and the runoff increase was found in Febuary-April and August due to the projected precipitation rise.

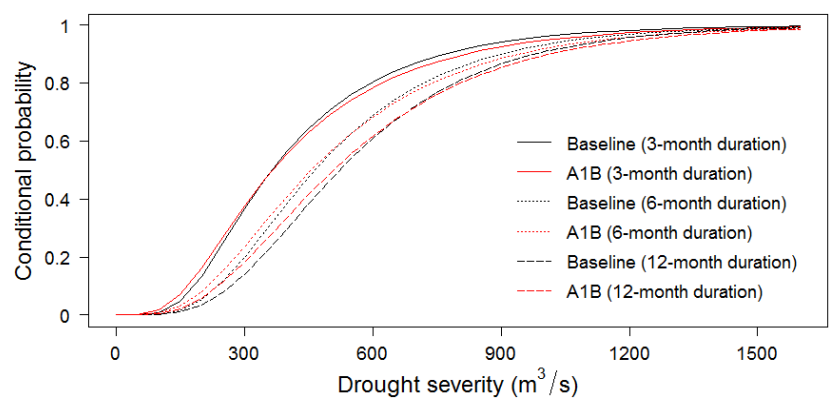

Figure 7. Conditional drought severity distributions given durations of 3, 6 and 12 months under baseline and A1B.

\subsection{Climate change impact on hydrological droughts}

The simulated monthly streamflow at the Huaxian station was used to derive the drought characteristics under baseline and A1B scenarios, and the identified properties of hydrological drought events were employed for univariate and copula-based bivariate drought analysis.

\subsubsection{Univariate drought analysis}

According to the theory of runs, 49 and 54 hydrological drought events were identified for baseline and A1B scenarios. The mean drought severity is $215 \mathrm{~m}^{3} \mathrm{~s}^{-1}$ for baseline and $221 \mathrm{~m}^{3} \mathrm{~s}^{-1}$ for A1B, with the latter being slightly higher than the former. Both scenarios are similar in mean drought duration, being 3.0 months for baseline and 2.9 months for A1B. Figure 4 shows that more drought events with higher severity (e.g. larger than $600 \mathrm{~m}^{3} \mathrm{~s}^{-1}$ ) are likely to occur under A1B, relative to the situation under baseline scenario. In addition, slightly more drought events with shorter and longer durations (e.g. $\leq 3$ months and $\geq 9$ months) are projected under A1B (Fig. 4).

For univariate drought analysis, the exponential and Weibull distributions were adopted to fit drought duration and severity for both scenarios. The Chi-square test was used and proved that the exponential distribution is able to effectively represent the distribution of drought duration for the events under both scenarios at a $5 \%$ significance level. Similarly, all four statistical tests, such as the KolmogorovSmirnov, Cramer-von Mises, Anderson-Darling and LiaoShimokawa tests, proved that drought severity can be accurately fitted by the Weibull distribution at the same significance level. With these theoretical distributions, drought characteristics associated with different return periods were derived. Table 2 shows that drought severity under A1B in all return periods would increase by $2.6-8.0 \%$. However, both scenarios have the same drought durations in all return periods, except for the 5-year event under A1B with a decrease in duration by 0.1 month (Table 2). This univariate drought analysis implies that future climate change under A1B would deteriorate the drought situation in the Weihe River basin, es- 


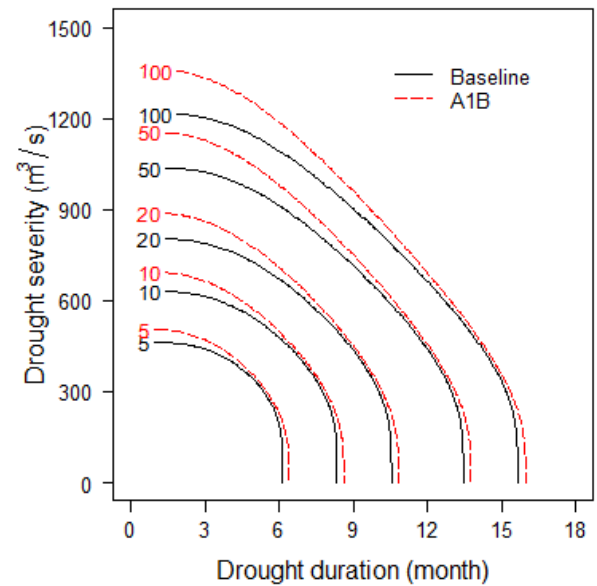

(a)

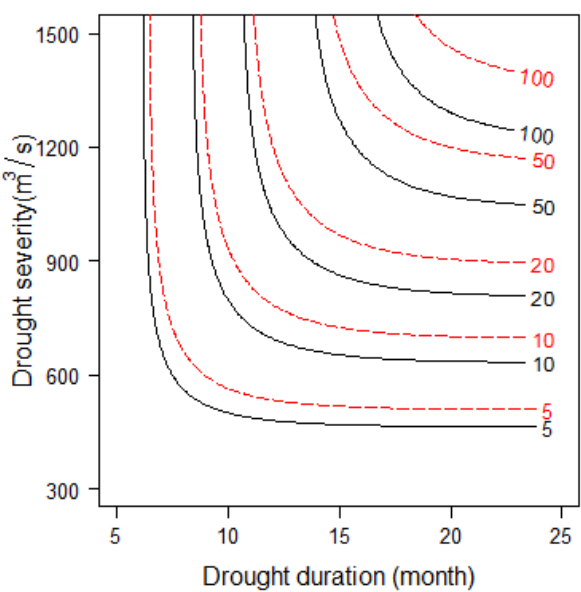

(b)

Figure 8. Contours of joint return periods for drought duration and severity for baseline and A1B drought events: (a) $T_{\mathrm{DS}}^{\mathrm{AND}}$ defined by Eq. (2) and (b) $T_{\mathrm{DS}}^{\mathrm{OR}}$ defined by Eq. (3).

pecially with increased frequencies of extreme hydrological drought events with high severity.

\subsubsection{Bivariate drought analysis}

To derive the joint distribution of drought severity and duration under both scenarios, four copula functions were adopted, namely Gumbel-Hougarrd, Clayton (CookJohnson), Frank and Ali-Mikhail-Haq copulas. The root mean square error (RMSE) was used to calculate the biases between the empirical and theoretical joint distributions. Table 3 shows that the Clayton copula has the lowest RMSE among all the four copulas, and the correlation coefficients between the empirical probability and the clayton-based theoretical joint probability are 0.995 and 0.983 , respectively, for baseline and A1B (Fig. 5). Therefore, the Clayton copula was adopted for bivariate drought analysis.

Figure 6 shows the contours of joint probability for drought duration and severity for baseline and A1B drought events. It demonstrates large distances between the contours for baseline and A1B drought events with the higher joint probabilities, especially in the cases of the contours with the probabilities of $0.90,0.95$ and 0.99 . On those contours at the same probability levels, if the same duration is given for both baseline and A1B events, the corresponding severity under $\mathrm{A} 1 \mathrm{~B}$ is found to be considerably higher than that under baseline. As a result, more severe extreme drought situations was projected under A1B scenario. This phenomena can be also illustrated by the conditional drought severity distributions given certain durations (Fig. 7). For example, given 3-month duration, the conditional probability of baseline events with severity less than or equal to $800 \mathrm{~m}^{3} \mathrm{~s}^{-1}$ is approximately 0.91. However, for A1B events, the same probability cor- responds to the drought with severity less than or equal to $860 \mathrm{~m}^{3} \mathrm{~s}^{-1}$.

Figure 8 shows the contour plots of severity-duration joint return periods, $T_{\mathrm{DS}}^{\mathrm{AND}}$ and $T_{\mathrm{DS}}^{\mathrm{OR}}$, for baseline and $\mathrm{A} 1 \mathrm{~B}$ drought events. It is found that A1B droughts are generally longer and more severe than baseline droughts. For instance, the drought with 3-month duration and $600-\mathrm{m}^{3} / \mathrm{s}$ severity leads to $T_{\mathrm{DS}}^{\mathrm{AND}}$ of 20.9 years and $T_{\mathrm{DS}}^{\mathrm{OR}}$ of 1.8 years for baseline period, whereas these return periods are projected to reduce to be 16.1 and 1.7 years under A1B scenario. Therefore, the projected drought events in the future would become more severe than the baseline droughts in the same bivariate return periods.

\section{Conclusions and discussion}

A framework to project the potential future climate change impacts on extreme hydrological drought events in the Weihe River basin in North China was established in this study. This framework includes: (1) the VIC large-scale hydrological model driven by climate outputs from PRECIS RCM for historical streamflow simulations and future streamflow projections; (2) the model for univariate drought assessment for drought properties (e.g. duration and severity) under historical and future climate; and (3) a copula-based model for joint duration-severity analysis. The univariate drought analysis projects that future climate change would lead to an increase in frequencies of extreme hydrological drought events with higher severity. The bivariate drought assessment using copula reveals that future droughts in the same return periods as historical droughts would be potentially longer and more severe, in terms of drought duration and severity. With this trend in the future, the hydrological drought situation in the Weihe River basin would be further deteriorated. 
The above framework shows that the possible climate change impacts on hydrological droughts largely rely on the projected streamflow under future climate scenarios. To project future streamflow, a modelling chain is usually adopted, which includes emission scenarios, climate models with statistical or dynamical downscaling schemes, and hydrological models etc. Each chain element is a non-ignorable uncertainty source influencing the projected river flow. Recently these multiple uncertainty sources and their contributions to the total uncertainty of the projected future river flow have been investigated. Prudhomme and Davies (2009) revealed that GCMs are the dominant uncertainty source in four mesoscale British watersheds and uncertainty due to emission scenarios are considerable. Bosshard et al. (2013) found that in general climate models are the dominant source in summer and autumn in a Swiss catchment. Dobler et al. (2012) demonstrated that the high uncertainty in hydrological projections is mainly due to the choice of GCM and RCM in an Alpine catchment in Austria. Therefore, considering that GCMs and RCMs are genarlly the dominant uncertainty and uncertainty from emission scenarios is negligible, it is necessary to access the possible impacts of future climate change on streamflow and hydrological droughts with multiple climate model simulations under multiple emission scenarios. Furthormore, the choices of various distribution functions for univariate drought frequency analyses and copula functions for multi-variate drougt evaluations might contribute considerably to the total uncertainty in the projected future drought events. Thus drought projections should be also conducted by multiple drought analysis methods in the future work so as to improve the reliability of this study.

Acknowledgements. This study is sponsored by the National Key Technology R\&D Program of Ministry of Sciences and Technology, China (Grand No. 2013BAC10B02), the Special Fund of State Key Laboratory of Hydrology-Water Resources and Hydraulic Engineering (Grand No. 20145031112), and the National Natural Science Foundation of China (Grant No. 41323001).

\section{References}

Bosshard, T., Carambia, M., Goergen, K., Kotlarski, S., Krahe, P., Zappa, M., and Schär, C.: Quantifying uncertainty sources in an ensemble of hydrological climate-impact projections, Water Resour. Res., 48, 1523-1536, 2013.

Dobler, C., Hagemann, S., Wilby, R. L., and Stötter, J.: Quantifying different sources of uncertainty in hydrological projections in an Alpine watershed, Hydrol. Earth Syst. Sci., 16, 4343-4360, doi:10.5194/hess-16-4343-2012, 2012.

Liang, X., Lettenmaier, D. P., Wood, E. F., and Burges, S. J.: A simple hydrologically based model of land surface water and energy fluxes for general circulation models, J. Geophys. Res., 99, 14415-14428, 1994.

Metoffice: PRECIS-Update. Metoffice, London, 2002.

Prudhomme, C. and Davies, H.: Assessing uncertainties in climate change impact analyses on the river flow regimes in the UK. Part 2: Future climate, Clim. Change, 93, 197-222, 2009.

Shiau, J., Feng, S. and Nadarrajah, S.: Assessment of hydrological droughts for the Yellow River, China, using copulas, Hydrol. Process., 21, 2157-2163, 2007.

Sklar, K.: Fonctions de reparitition å $n$ dimensions et leura marges, Publications de l'Institut de Statistique de L'Université de Paris, 8, 229-231, 1959. 